\title{
Full-immersion virtual reality for experiential education: An exploratory user experience analysis
}

\author{
Christian Schott, Stephen Marshall \\ Victoria University of Wellington
}

\begin{abstract}
Experiential education is widely considered an effective pedagogy to foster learning for our rapidly changing world. Despite this, residential fieldtrips are on the decline. Recent advances in full-immersion virtual reality (VR) technology offer great potential to make situated experiential education, such as fieldtrips, more accessible to educational institutions, however, research on VR technology's effectiveness in this context is lacking. This article documents exploratory action research which examines the effectiveness of full-immersion VR technology for experiential education by adopting a user experience (UX) analytical frame. Six university staff and five students who participated in a trial of a virtual environment developed for sustainable tourism education, discussed their user experience through semi-structured interviews. The UX lens which distinguished between three UX facets during the analysis, beyond the instrumental, emotion and affect, experiential, serves to identify research areas requiring attention and assists in the technology's improvement prioritisation. Interviews revealed many positive perspectives thus lending support to VR technology's suitability to foster experiential education, however, several negative experiences were also identified; principally motion sickness. The exploratory findings suggest that more research is warranted to more comprehensively examine VR technology's capacity to foster experiential education and locate VR's place in the education landscape.
\end{abstract}

Implications for practice or policy:

- UX should be enlisted more widely to analyse virtual reality technology's capacity to foster situated experiential learning.

- Developers of virtual reality learning tools should consider the three UX facets from the beginning of new projects. The adapted UX framework can serve to crystalise user experiences into their positive and negative components.

- The adapted UX framework can guide the user-informed prioritisation of refinements to virtual reality-based learning tools.

Keywords: experiential education, full-immersion, virtual reality, user experience, UX, tourism, qualitative

\section{Introduction}

We live in a rapidly changing world characterised by environmental change, societal change, and rapid technological development, to name but a few drivers. As educators we need to move with these changes to keep educational content relevant. A pedagogy recognised as well-suited to a changing world is experiential education (EE), which was first promoted early last century by John Dewey (Dewey, 2004), and has since been applied from primary through to tertiary education, as well as across many disciplines. Its suitability for a rapidly changing world stems from its emphasis on connecting the learner to the contemporary world coupled with the learner actively driving the learning process (Dewey, 2004), thus fostering lifelong learning skills (Trinh, 2019). EE has also been credited with assisting students in developing critical reflection as well as analytical skills (Dewey, 1938; Kolb, 1984).

Despite EE's pedagogical value for today's learners, situated forms of EE, including fieldtrips and site visits, have been in decline at many universities owing to a combination of liability concerns (Pearson \& Beckham, 2005), budget constraints (Stainfield et al., 2000), and competing pressures on staff time (Dredge $\&$ Schott, 2013). At the same time technological advancements over the last 5 years have provided new opportunities to foster EE; most notably through full-immersion virtual reality (VR) technology which provides the learner with a fully immersive (visually and auditory) experience of a space or place. While 
VR technology is not new, it has become far more accessible to educators over the last 5 years because of the increased affordability of VR headsets coupled with considerable improvements in user experience (Jensen \& Konradsen, 2018). In view of the pedagogical merits of EE, the decline in situated forms of EE (such as class fieldtrips), and the improvements and increased accessibility of VR technology, a critical examination of VR technology as a means to foster EE is warranted. The multidisciplinary field of humancomputer interaction (HCI) offers valuable research guidance for this complex topic and has recently embraced the user experience (UX) concept (Forlizzi \& Battarbee, 2004; Hassenzahl, 2003; Hassenzahl \& Tractinsky, 2006) in recognition of the importance of experience and emotion in HCI (Vermeeren et al., 2016). Within the UX literature, Hassenzahl and Tractinsky's (2006) conceptualisation has resonated the most with researchers as it synthesised a wide range of previous UX studies in order to devise a comprehensive new UX conceptualisation. To allow for a critical and nuanced exploration of fullimmersion VR technology for experiential education, this paper adapts Hassenzahl and Tractinsky's (2006) conceptualisation of UX to deepen our understanding of the reported strengths and weakness of VR technology for EE. In summary, this exploratory research examines the effectiveness of full-immersion VR technology for experiential education by adopting a UX analytical frame.

\section{Literature review}

The pedagogy of EE is supported by literature spanning many decades (Allison \& Seaman, 2017; Dewey, 2004; Kolb, 1984; Wurdinger \& Rudolph, 2009) and emphasises the active and reflective nature of learning (Dewey, 2004). It is conceptualised as an alternative to didactic educational approaches both in philosophical and practical terms, but it also differs from vocational training through its strong learning focus on subject area mastery, social-emotional growth, and self-awareness amongst others (Allison \& Seaman, 2017). Itin (1997) defines experiential education as "a holistic philosophy, where carefully chosen experiences supported by reflection, critical analysis, and synthesis, are structured to require the learner to take initiative, make decisions, and be accountable for the results" (p. 6). He further elaborates that the resulting intellectual, emotional, social, political, spiritual, and physical engagement of learners in a complex and uncertain environment serves to provide a strong context for learning. For a succinct overview of EE's philosophical underpinnings see Allison and Seaman (2017) and Roberts (2018) for EE's benefits to contemporary higher education, which include not only pedagogical merits but also that it serves institutional interests (Roberts, 2018). From a learning and teaching perspective the benefits are numerous and include increased student engagement (Hanson \& Moser, 2003), deeper subject understanding (Chickering \& Gamson, 1987), increased student success (Roberts, 2018), and ultimately the development of lifelong learning skills (Trinh, 2019). At the same time institutions also see benefits in offering EE. For instance, Roberts (2018) argues that EE addresses the widely held concern that universities do not adequately prepare students for the world of work while also noting that community-based EE projects assist in good public relations and outreach for higher education institutions.

In many disciplines and subject areas, it is important to situate the learning experience in the most meaningful cultural, political, economic, social, and environmental context because the context will have a bearing on the learning experience and outcomes (Schott \& Marshall, 2018). Situated learning theory posits that much of what is learned is specific to the situation and place in which it is learned (Greeno et al., 1993). Proponents of this pedagogical approach argue that learning should take place in the real world as abstract and decontextualized learning leads to difficulties when trying to apply acquired knowledge and skills(Choi \& Hannafin, 1995).

In contrast to the EE literature, which spans more than 4 decades, the literature on immersive experiences in education is still comparatively nascent. In the context of education, the term immersion has been conceptualised as a powerful mode of engagement where natural sensorimotor systems are used to deliver information interactively (Slater \& Sanchez-Vives, 2016). The ability to immerse students within a particular context constitutes a valuable educational tool that engages and provides rich and complex information supporting a range of cognitive, affect, and skill outcomes (Dalgarno \& Lee, 2010). While in many cases a real (non-virtual) situated learning experience is likely to deliver the richest outcomes, virtual learning environments nevertheless offer a range of benefits including those of a pedagogical, logistical, and even ethical nature (Schott, 2017). These benefits include, on the one hand opportunities to negotiate the main constraints of real fieldtrips, such as time and budget constraints, while on the other enabling students to virtually immerse themselves in difficult to access or dangerous environments (Schott \& Marshall, 2018). These environments include places where practical or ethical concerns preclude students 
from visiting, such as to avoid significant impacts on the climate, fragile environments, and socio-cultural fabric of (small) communities (Buckley, 2000; Schott, 2015), or places lost as a result of natural disasters or human action (Freina \& Ott, 2015; Slater \& Sanchez-Vives, 2016).

Technology provides a variety of strategies for immersion. The simplest interactive systems are commonly described as computer simulations, where a computer provides an interactive environment representing an underlying model such as a business system (D'Angelo et al., 2014). Computer simulations provide a mechanism for students to explore a complex but bounded space in a way that can provide a limited form of immersion. Based on a review of the literature, Hew and Cheung (2010) suggest three main pedagogical uses of simulation technologies: experiential spaces; simulation of spatial environments; and communication or socialisation. Loke (2015) in a review of pedagogical approaches supporting the use of VR suggests that the majority of educational applications are based on constructivism (Piaget, 1976), experiential education (Dewey, 2004), and the related field of situated cognition (Choi \& Hannafin, 1995). This is consistent with the earlier work of Sitzmann (2011) whose review of computer-based simulation games found them to be effective, provided that the approach was driven by an active learning pedagogy (Bonwell \& Eison, 1991).

Virtual reality was first described with that name in the 1980's by Lanier (1989) who built on a conceptualisation from the 1960's by Heilig (1962), with the Sensorama, and Sutherland's (1965) early work in computer interfaces. In its modern sense, VR provides as basic affordances an illusion of 3-D space, a representation of the user in that space, and tools for manipulating the environment, including communication with other users (Dickey, 2005). The software used to create the VR illusion also defines the affordances that a user can engage with through a diverse selection of hardware interfaces such as hand units, gloves, body suits, head mounted displays, and external sensors. Typically, these provide users with the ability to move, interact with or manipulate simulations, and engage with other users.

Educational use of VR has been shown to support context-specific and situated learning through immersive experiences, visualisation of invisible or abstract concepts, exploration of content in multiple dimensions and from multiple perspectives, provision of in-context real-time formative feedback, collaborative learning, and the negotiation of barriers including time, physical accessibility, safety, and ethical concerns (Freina \& Ott, 2015; Hew \& Cheung, 2010; Lombard \& Ditton, 1997; Schott, 2017; Tussyadiah et al., 2018). Current VR environments remain limited by the complex interfaces and the lack of familiar controls such as keyboards. The computational demands of responsive high-resolution rendering needed to avoid motion sickness is also a problem, requiring either the use of expensive hardware and umbilicals, or a compromised experience through the use of cheaper mobile devices with lower performance; the rapid growth of the market is expected to address these issues relatively soon (Martin-Gutiérrez et al., 2017).

The fully virtual world provided by full-immersion VR enables a user to feel the present. "[S]patial immersion occurs when a player feels the simulated world is perceptually convincing, it looks 'authentic' and 'real' and the player feels that he or she actually is 'there"' (Freina \& Ott, 2015, p. 1). This sense of being there (Cummings \& Bailenson, 2016), or place illusion (Slater, 2009), harnesses the users own cognitive systems to engage them in natural behaviour in response to simulated experiences (Shin, 2018; Slater \& Sanchez-Vives, 2016). Educational virtual worlds support a range of learning modes (Dalgarno \& Lee, 2010; de Freitas, 2008) by combining the dynamic display of information situated in real-world environments (representational fidelity) with features that respond to user actions (learner interaction). These modes support visual learning preferences through visual representations (Felder \& Spurlin, 2005; Hsu, 2011), kinaesthetic preferences by involving the learner physically with the to-be-learned information (Krätzig \& Arbuthnott, 2006), and inductive learning preferences through its problem-based approach (Prince \& Felder, 2006). The application of VR headsets to foster situated forms of EE has also been demonstrated to have strong merit (Schott \& Marshall, 2018). Further, VR has been found to stimulate students' motivation and academic performance (Bacca et al., 2014; Holley et al., 2016), and assist students in the development of social and collaborative skills (Martin-Gutiérrez et al., 2010), as well as support students in the acquisition of knowledge (Merchant et al., 2014). As a result, Slater and Sanchez-Vives (2016) argue that VR has the potential to support student learning in many educational fields.

In summary, the four major motivations for creating an immersive virtual education environment are aptly summarised by Freina and Ott (2015): (1) to provide learners with the ability to explore historical environments, (2) to overcome physical limitations such as access to remote environments, (3) to explore 
dangerous environments or situations safely, and (4) to overcome ethical limitations when engaging with experimental subjects. The virtual environment documented in this paper was developed as a combination of the second and fourth motivation; to access a remote destination that is challenging to reach with a class of 60-90 students and to overcome ethical concerns over the trip's negative environmental and sociocultural impacts on a small community.

\section{Theoretical positioning}

The theoretical framing for this paper originates in HCI, a field that has developed considerable maturity over the last decades and is now argued to be in its third wave (Bødker, 2015). A research branch within $\mathrm{HCI}$ that is rapidly developing to dominate the HCI field is UX because of the importance it places on experience and emotion in HCI (Vermeeren et al., 2016). UX provides a "fresh look" (Bødker, 2015, p. 91) at human-computer interaction and represents a counter-movement to the dominant, task, and work-related usability paradigm (Hassenzahl \& Roto, 2007; Hassenzahl \& Tractinsky, 2006). While many conceptualisations of UX are apparent in the literature (Bevan, 2009; Law \& van Schaik, 2010) a universally-accepted definition of UX is still absent (Rebelo et al., 2012). Against this backdrop Hassenzahl and Tractinsky's (2006) conceptualisation of the three facets of UX has become a widely-cited and adopted approach which has found application in a diverse range of disciplines. In their 2006 paper, Hassenzahl and Tractinsky conceptualise UX as "technology that fulfils more than just instrumental needs in a way that acknowledges its use as a subjective, situated, complex and dynamic encounter" (p. 95). Drawing on UX theories and categorisations from the literature, Hassenzahl and Tractinsky propose UX to consist of three facets guided by a positive focus on creating outstanding emotional experiences, rather than on adopting a mostly instrumental, task-oriented view of interactive products, which is a core criticism of traditional HCI (Bargas-Avila \& Hornbaek, 2012). Not surprisingly, the first facet responds to this criticism of traditional HCI and is termed beyond the instrumental. It incorporates aesthetics, a holistic approach, and hedonic qualities as features of the user experience. The second facet builds on affective computing (Picard, 1997) and extends emotion and affect to the user through positivity, subjectivity and the dynamic of antecedents and consequences. The third facet is the experiential, which emphasises situatedness and temporality, and is characterised by user experiences that are complex, situated, dynamic, unique, and temporally-bounded.

Despite prevailing evidence of full-immersion VR technology's potential to provide effective and meaningful EE (Freina \& Ott, 2015; Loke, 2015; Slater \& Sanchez-Vives, 2016), there are only few studies of this technology in the context of experiential education, and none that adopt the valuable UX perspective. Consequently, it is timely to explore full-immersion VR technology for fostering EE by adopting a UX lens to develop a nuanced understanding of the technology's strengths and weaknesses. Specifically, this article briefly documents the trial of full-immersion VR technology for EE, before it explores the user-generated strengths and weaknesses of this technology by adopting a UX perspective.

\section{Methodology}

Supported by a business faculty teaching innovation fund, this paper documents an exploratory UX research-driven trial of the Oculus Rift Dev2 VR headset. The research consisted of a trial of the VR headset to experience a Unity software-based virtual island in Fiji, followed by structured interviews with the trial participants about the user experience. The design of the virtual environment was guided by the pedagogy of EE with careful attention to the core characteristics of an experiential education environment: sense of immersion, complexity, and interaction (Schott \& Marshall, 2018). For instance, sense of immersion (Murray, 1998) was fostered primarily through visual immersion by replicating the real island's environmental features as well as buildings. This was enhanced through audio by incorporating sounds characteristic of the Fijian island (breaking waves and sea birds) as well as animated content in the form of birds, fish, butterflies etc. Complexity was incorporated as troublesome knowledge (Meyer \& Land, 2003) with the intention to help students develop their critical and creative thinking by embedding a range of stakeholder interviews representing differing views as well as highlighting negative implications that can flow from well-meaning management decisions. Closely aligned to the EE design the key learning goals were two-fold: (1) help learners develop a deeper understanding of the three pillars of sustainable tourism development (environmental, socio-cultural and economic considerations), (2) and assist them in unpacking the complexity and interwoven nature of the three pillars in the context of a small island developing nation (Prince \& Ioannides, 2017; Weaver, 2017). Tourism is an important feature of both the economic and social life of these nations, which is why sustainable development in the context of tourism was used as an 
example for the technology's application to higher education. Specific learning tasks were focused on exploring the island to understand its natural features as well as to engage with islanders through video capsules embedded into the landscape. For more details about the educational focus and objectives of the VR learning tool see Schott (2017) and for details about the pedagogical concept underlying the development of the VR learning environment and tool see Schott and Marshall (2018).

We adopted an exploratory action research methodology as it reflects close alignment with experiential learning as originally conceived of by Kolb (Miettinen, 2000). Describing the research as exploratory emphasises the inquiry that is being done with our participants as they engage with the virtual reality environment and respond to its affordances. Action research is defined by collaborative inquiry (Reason \& Bradbury, 2008) and the research undertaken in our exploratory examination is guided by the experience of participants, strengthening the experiential learning orientation of the pedagogical model being tested.

A selection of 11 academic, faculty leadership, and support staff who had previously expressed interest in teaching innovation were invited via email to participate in the project. Additionally, the project sought to incorporate the student voice by sending an email invite to a class of 60 second year Tourism Management students. In total 11 students and staff participated in the trial and subsequent in-depth interviews; 6 staff members and 5 students. The student respondents were all aged between 19 and 23 with cultural backgrounds reflective of the broader student characteristics at the authors' university: 2 were of New Zealand European/pakeha background, and 1 each of New Zealand Maori, Fijian, and Asian cultural background. The gender balance was also reflective of the broader student cohort with 3 female and 2 male student respondents. Staff respondents, with the exception of a staff member in his early 30 s, were all aged over 50. This respondent group was evenly balanced in gender terms and also included cultural backgrounds broadly reflective of the authors' New Zealand university: 3 staff respondents were of New Zealand European/pakeha cultural background, 2 were of European cultural background, and 1 of New Zealand Maori cultural background. The staff roles were intentionally diverse because education in its broader sense is not solely the role of the teacher (Louis \& Gordon, 2006). Staff respondents included an associate dean, several academic staff (with teaching and research responsibilities), and 2 professional staff with support roles in IT and student learning and wellbeing support. None of the respondents had used a VR headset before the trial. Each VR trial lasted between 10 and 20 minutes. It commenced with one of the researchers introducing respondents to the headset and movement controls, before respondents were provided with an overview of the virtual environment. Respondents were then asked to explore the island freely. In addition to exploring a large space consisting of a small Fijian village with a church, community hall, kindergarten and houses, respondents could also watch video interviews with community members that were posted around the island (embedded where they were recorded). Furthermore, respondents could walk down to the beach and watch the waves breaking or walk to the top of a hill overlooking the village with sea birds squawking and circling overhead. Most respondents explored the virtual island for 15 to 20 minutes with only two concluding the trial after about 10 minutes. In all cases it was the respondents who decided when to conclude the trial; the two respondents who concluded the trial after 10 minutes were strongly affected by motion sickness and wished to stop as a result (discussed in the findings). Because of the previously unchartered nature of the research, coupled with respondents deciding when to conclude the trial, the trial duration of 10 to 20 minutes was deemed sufficient for the purposes of this exploratory research project.

After the trial, semi-structured interviews lasting on average 20 minutes were conducted with each respondent. The interviews explored how respondents experienced the visit to the virtual island by asking broad questions about what the respondents considered to be positive and negative aspects of the experience. The interviews were audio recorded, transcribed, and subsequently analysed in Nvivo using exploratory thematic analysis (Braun \& Clarke, 2006; Edgar \& Manz, 2017). The analysis consisted of a two-step process. The first step combined inductive and deductive reasoning (Fereday \& Muir-Cochrane, 2006) in the development of positive and negative user experience themes, which were informed by the interviews as well as the related literature. Subsequently, the identified themes were mapped onto a three axes adaptation of Hassenzahl and Tractinsky's (2006) UX conceptualisation. In the adaptation (Figure 1) each axis represents one of the three UX facets: the experiential facet (dynamic, complex, unique, situated, temporarily-bounded), the emotion and affect facet (subjective, positive, antecedents and consequences), and the beyond the instrumental facet (holistic, aesthetic, hedonic). Each of the three axes ranges from -5 (negative), to 0 (neutral), and to +5 (positive). Due to the project's exploratory and qualitative approach this mapping process is intended to be indicative and to inform further debate, rather than to follow a scientific process. As such the statements relating to each theme were synthesised into a broad positioning 
to reflect how users responded to the trial in the context of each of the three adapted UX axes: positive $(+3$ to +5$)$, moderately positive $(+1$ and +2$)$, neutral $(0)$, moderately negative ( -1 and -2$)$, and negative $(-3$ to 5 ). Each identified theme is represented by a sphere in the diagram (Figure 1), the size of which is representative of the number of respondents that highlighted the theme. Sphere sizes range from the largest sphere representing 10 of the 11 respondents (sense of place theme) through to the smallest sphere representing 2 respondents (hyperreal appearance theme).

The virtual island was digitally recreated based on a real Fijian island using the Unity software platform. As previously outlined, key features relevant to EE were paid careful attention to: geographic features and topography, range of natural and human made features, and vegetation, as well as the island's community which was represented through embedded videos of community members. To present a range of diverse stakeholder views authentically, more than 10 videos were embedded in the virtual island, each containing different perspectives on life on the island as well as the costs and benefits that arise from tourism on the island. The virtual Fijian island is comparatively large as it takes 2 minutes and 40 seconds to walk from one end of the island's village past the community hall to the beach on the other side of the village; for more information about the development of the virtual island see Schott (2017).

\section{Results}

\section{Predominantly positive user experiences}

Several themes representing positive experiences of the VR-based EE environment emerged from the interviews. They are visualised in Figure 1 according to their UX facet positioning and include sense of place, sensory appeal, natural movement, learning enrichment, and comprehensive vision.

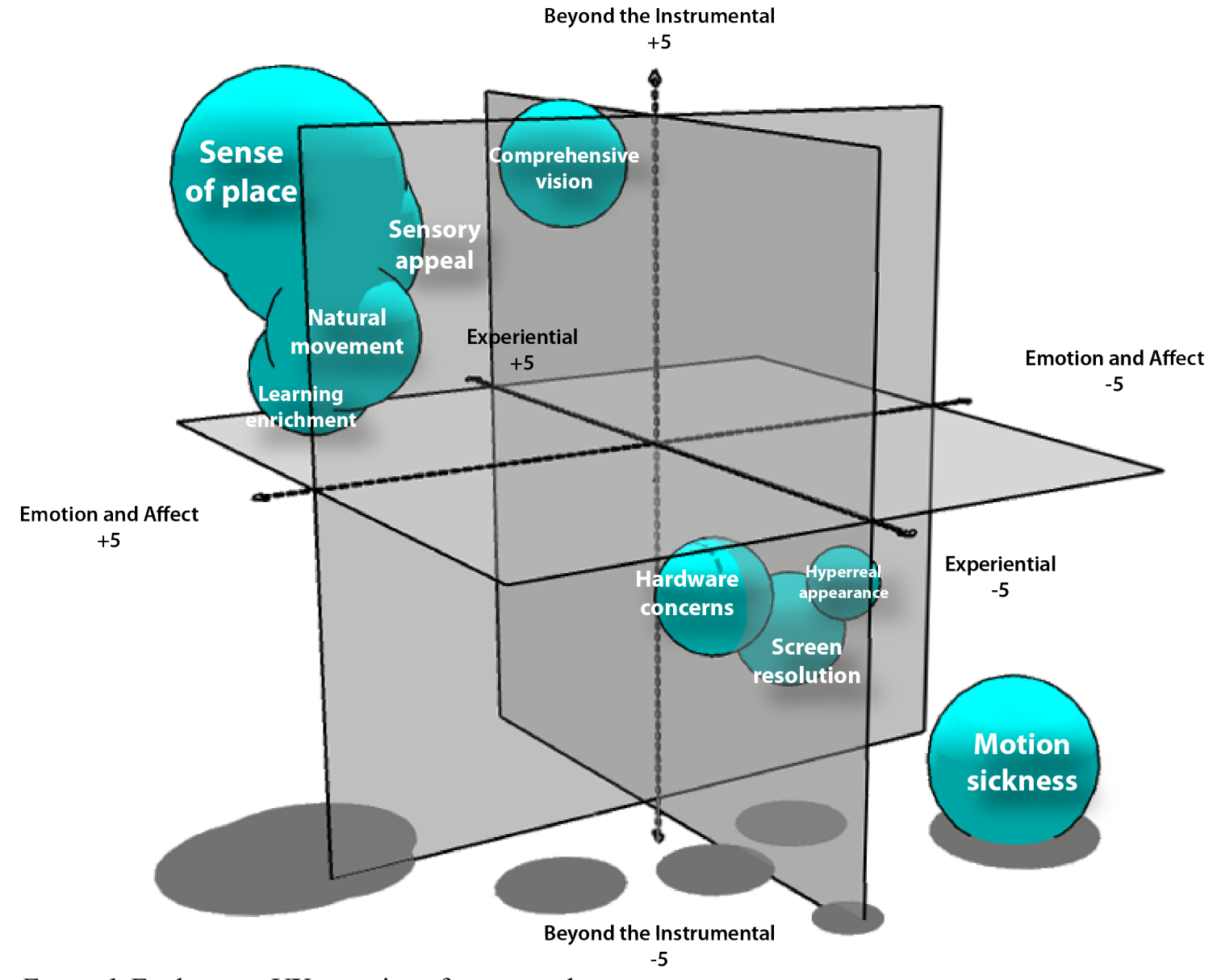

Figure 1. Exploratory UX mapping of response themes 


\section{Sense of place}

This theme was mentioned by 10 of the 11 respondents and positioned as positive on the experiential facet and as moderately positive on the emotion and affect as well as the beyond the instrumental facets (Figure 1). The associated respondent comments focused on how strongly they felt they were there on the Fijian island (Freina \& Ott, 2015), thus emphasising a strong sense of presence. Most comments framed sense of place in terms of a holistic immersive experience of the virtual island, as exemplified by this quote: "when I ran out to the pier you could stand on the pier, with the sounds of waves crashing against it, looking back at this massive, expansive coastline and village ... it was amazing". A smaller number of respondents (4) also commented on the animated content (waves, seabirds, butterflies, fish, chicken, and falling leaves) and the associated sound as very powerful in creating a sense of place "the fact that you can look up in the sky and see the birds and you can actually see the fish. At one point I was walking through a bush, the flaxes and whatnot and the butterflies, to me that was quite awesome". Closely aligned with the experiential UX facet, the term "real" was commonly used by respondents.

\section{Sensory appeal}

Sensory appeal was the second most frequently reported theme, discussed by 8 of the 11 respondents. Because of the overarching influence of positive sensory experiences in terms of all three UX facets this theme is positioned as positive on all three axes (Figure 1). While there is overlap with the sense of place theme discussed above, sensory appeal was explicitly highlighted and discussed as a separate point. The visual domain was identified as the strongest feature in this context due to a high degree of detail, a strong depth perception, and the strong appeal of (familiar) colours. In particular, the colour of the sky and sea were expressed as providing a true sense of the Pacific island, as well as a sense of relaxation: "I like walking along the beach because the ocean is bright blue". Several parts of the virtual island also contained animated features as described earlier, which was noted by users to be enhancing the appeal of the experience. The holistic visual impact of familiar colours, a strong depth perception, and familiar animated features are vividly expressed in this quote: "one of the things I love is the waves washing up and the beautiful view of the sea".

However, sensory appeal was also discussed with reference to the auditory domain, which was catered to via ambient sound as well as the voices of the stakeholders in the embedded videos. The ambient sounds included the sound of waves and the cry of seabirds, which were described as very powerful sensory stimuli: "the seabirds squawking...the sounds are pretty evocative and it takes you to a different place". Unexpectedly three respondents also made reference to the tactile domain in that they felt stimulated to try to touch objects, a feature of the beyond the instrumental facet. The multi-sensory stimulation offered by the virtual world then had a profound effect on respondents, of which several discussed not only the desire to touch items but also reported muscular and skin responses. The following quote illustrates that despite Loke's (2015) scepticism the virtual experience can evoke a physical response:

As soon as you started walking it almost felt like phantom legs moving, I could feel my muscles are almost moving...I think it's incredibly realistic... there was a weird tingly sensation in my knees and my legs as I was walking through the grass, because it felt like there should be something there.

In summary, this theme appeals to three senses rather than the anticipated visual and auditory domains; although to differing degrees. Sensory appeal was discussed in a holistic, aesthetic, situated, dynamic and positive manner, thus positioning it as positive on all three UX facets.

\section{Natural movement}

The natural feeling of head movement in world was mentioned by 6 respondents who had a strongly positive response to this intuitive feature of the VR experience. The theme is positioned as positive on the emotion and affect axis owing to this type of commonly provided comment, "turning your head, amazing", while it is mapped as moderately positive on the beyond the instrumental and the experiential axes due to its comparatively lower hedonic and dynamic traits. An unexpected experience was shared by one of the student respondents with extensive gaming experience who reported that she had to unlearn gaming commands: "for moving I was just wanting to move the joystick but I kept having to move my head which 
took some time to get used to it". This is a useful reminder that not all users will automatically use realworld physiological actions but may instead be inclined to initially apply their digitally-anchored physiological responses when inhabiting a digital world.

\section{Learning enrichment}

This theme was discussed by 5 respondents and positioned as positive on the emotion and affect and experiential axes owing to comments about the highly positive and motivating impact, as well as about the complex and contextualised nature of the virtual island. On the beyond the instrumental axis this theme is positioned as moderately positive. Aligned with this UX positioning, key strands in this theme are: the visual nature of learning, the strong experiential component, the holistic learning experience, and the impact on motivation to learn. Each of these learning-related strands are now briefly discussed in turn.

The visual learning process fostered by the VR headset appealed strongly to four respondents, of which one explained vividly how the VR environment positively influenced her learning:

I am more of a visual learner... what you get with all the other classes, is books and chapters that you have to read through and half of it doesn't even sink in. But when you do this, you get to visualise everything and you get to listen while they speak to you. I definitely think that I would learn a lot more with this way (VR) than any other way.

The related experiential component was explicitly discussed by three respondents, who contrasted the VR experience with familiar text-based case-studies: "because I don't like reading, I found the actual experiential component more engaging". The personal and user-controlled exploration and learning about a reality-informed island was also mentioned. Additionally, the holistic learning experience fostered by the technology was also highlighted during the interviews:

You are getting the visuals which give a broader sense of the culture of the island, physical space, the benefits and constraints of that space... so I think its strength is giving students a whole range of information, more than they would get from a [written] case study. And then allowing them to make the most of that information.

The final strand in the learning enrichment theme, impact on motivation to learn, is arguably the most important facilitator of learning (Wlodkowski, 2011). For most learners the motivation or lack of motivation to learn will be the gatekeeper of whether any learning takes place. Although this learning strand was implicit in 5 of the respondents' interviews it was directly addressed by only 2 :

By doing things [in a virtual world], it makes it a lot more interesting for students. Then they want to learn, and they want to because it's fun and it's kind of like, you don't realize you are learning while you are doing it.

This comment is a powerful endorsement of EE through full-immersion VR technology. Meaningful learning that takes place because of the learner enjoying the process is arguably a forte of any learning tool.

\section{Comprehensive vision}

The least commonly discussed theme was comprehensive vision, which was mentioned by 4 respondents. The theme is positioned in the positive range on the beyond the instrumental axis due to its holistic and hedonic traits, while it is placed as moderately positive on the emotion and affect, and experiential axes owing to its only moderately positive affect and experiential user experience (Figure 1). In particular two features of the virtual island were highlighted as positive: (1) a strong depth perception that underscored a sense of engagement with the virtual environment, and (2) a strong sense of visual immersion offered by the headset's comprehensive vision. The latter point was clearly articulated by this respondent: "it is just so immersive. You really do get the feeling that you are surrounded by the image". This statement emphasises the importance of (in-world) peripheral vision in creating a positive and holistic user experience. 


\section{Predominantly negative user experiences}

Alongside the many predominantly positive themes four primarily negative experience themes were also identified by the respondents. These themes are again illustrated in the context of the three UX facets in Figure 1 and include, in order of importance, motion sickness, hardware concerns, screen resolution, and hyperreal appearance.

\section{Motion sickness}

The negative experience of motion sickness overshadowed the entire trial, as reflected by its positioning at the extreme ends of the negative range on all three UX facets (Figure 1); it was reported as debilitating by three respondents. Seven of the 11 respondents reported feeling some level of sickness during the trial; half reported experiencing motion sickness at the beginning with it subsiding after a few minutes, whilst the other half felt fine for the first few minutes and then started experiencing it. The user response then differed quite markedly and a tentative age-related trend emerged. The younger respondent group (students) experienced a moderate level of motion sickness at the outset, which dissipated after a few minutes, while the older respondents (staff) reported a more severe onset of motion sickness which only started after 3 to 5 minutes. In the latter case the motion sickness reportedly continued for an hour or more after removing the headset. The severity of the motion sickness reported by three respondents in the older age group cannot be understated as the nausea rapidly started to overshadow the experience itself: "the biggest thing was just the motion sickness for me. That keeps you from enjoying what you are doing because you are concentrating on not being ill". The 4 respondents entirely unaffected by motion sickness were all comparably young (19-28 years).

\section{Hardware concerns}

Hardware concerns were reported by 4 respondents and included concerns about the user comfort of the headsets as well as of the process of note-taking. This theme was positioned as moderately negative in the context of the beyond the instrumental and experiential axes. This is due to concerns about the weight and fit of the VR headset as well as the inability to take notes. With regard to the emotion and affect facet the theme was positioned in the neutral space at the centre of the axis. Discomfort while wearing the headset was highlighted by 2 respondents, and a further 2 observed that it was not possible to take handwritten notes while wearing the headset. As this trial sought to explore positive and negative user experiences in the context of experiential education this concern is not trivial and will need to be considered carefully by educators; although alternative approaches to handwritten note-taking are easy to access.

\section{Screen resolution and hyperreal appearance}

The other two themes revolved around visuals. They comprised of concerns about screen resolution, which was mentioned by four respondents, and the manner in which the virtual world is presented, discussed by 2 respondents. Screen resolution, which was positioned as moderately negative for all three UX facets, was discussed to be negatively impacting respondents' ability to focus on objects in the distance due to pixilation: "I found that it was sometimes difficult to see, the graphics were easier to see close up ... than in the distance", as well as generally being demanding on the eyes. The final theme, hyperreal appearance, was mentioned by 2 respondents and is predominantly a function of how the virtual island had been developed. The theme was positioned as negative on the experiential facet due to the virtual island being perceived as too clinical. The hyperreal appearance was reported to be distracting and thus positioned as moderately negative on the emotion and affect, and beyond the instrumental axes. One respondent focused in particular on colours appearing more vibrant than in reality: "the weakness was around that artificiality and hyper reality". The other was critical of the virtual island's pristineness: "there's no litter on the ground, it is all nice and clean ... it looks too much like a Hollywood image of a tropical island, where everything is perfect". While both comments are important in the development of EE virtual environments, the latter quote is particularly significant if the aim of the virtual environment is to recreate a real place or time period. With the current state of technology, the realities of contemporary island life and tourist activity, such as rubbish, can be meaningfully incorporated into the VR island, however such detailed development work increases the project costs considerably and the budget to develop the virtual island was highly constrained. 


\section{Discussion}

These exploratory findings suggest that full-immersion VR experiential education offers educators a valuable mechanism for students to access reality-informed places and pedagogically-framed learning experiences. One of the broader benefits of full-immersion VR technology is that it addresses the three challenges faced by real fieldtrips when seeking to provide EE. For instance, in response to Stainfield et al.'s (2000) budget concern, VR-based EE is arguably less cost intensive than flights and accommodation for an entire class of students, particularly when using the same VR hardware over several years. Additionally, students are not exposed to situations and environments which carry an increased risk of accidents or raise liability concerns (Pearson \& Beckham, 2005). And finally, large groups of students can experience the virtual environment and engage with the recreated place and its people, without the necessity for a (carbon-emitting) flight (Schott, 2017).

Figure 1 highlights that respondent feedback about the virtual island included both predominantly positive as well as primarily negative user experiences, as mapped against the adapted three UX axes. The fact that several negative user experiences were reported is not unusual as setbacks are an integral part of the innovation process (Khanna et al., 2016). Indeed, each theme's detailed UX conceptualisation across the three adapted facets should prove valuable in identifying and prioritising refinement efforts to mitigate the negative experiences. Notwithstanding the discussed weaknesses, the feedback was predominantly positive and full-immersion VR technology was identified to offer a range of positive affordances in support of EE. This was not only illustrated by several themes'positioning in the positive range on the experiential UX axis, but also in terms of the same themes' positive placing on the beyond the instrumental and emotion and affect axes. For instance, the natural feeling enabled by the headset's responsiveness allowed for instinctive movement to be possible in the virtual world, which together with the comprehensive field of vision had a profoundly positive impact on the user, their sense of immersion, and ultimately their sense of being there (Cummings \& Bailenson, 2016). Equally, the sensory appeal of 3D high resolution visuals coupled with situated animated content, such as seabirds and waves supported by fitting sound, was also reported to contribute to a strong sense of place illusion (Slater, 2009).

In addition to the visual and auditory domains commonly incorporated in VR experiences there is an increasing drive in $\mathrm{HCI}$ to also incorporate the tactile, olfactory, and even gustatory domains (Obrist, 2017). Catering to these senses in the design of VR EE environments would enhance the experiential and beyond the instrumental UX facets in particular and thus amplify the overall user experience. For instance, the tactile domain could be incorporated through the use of a small selection of meaningful items, such as kava bowls in the case of the Fijian island as they represent an important part of a Fijian isevusevu (traditional welcoming ceremony) (Vunidilo, 2010). Equally olfaction (Kaye, 2004), which has been shown to be a powerful cue for information recall (Aggleton \& Waskett, 1999), could be incorporated into a virtual world in both a holistic fashion, such as the smell of the sea breeze across the whole island, as well as in a targeted manner through the smell of a wood fire in a particular location. Vi et al. (2017) have explored also the use of gustatory cues in $\mathrm{HCI}$ and identified two delivery approaches; via a mouthpiece and contactless delivery. Both could be adapted for VR and would likely enhance the beyond the instrumental and experiential UX facets.

The holistic and aesthetic nature of the learning environment, exemplified by a positive position on the beyond the instrumental UX facet, coupled with a positive positioning of the active learning approach on the emotion and affect UX facet, align with Sitzman's (2011) argument that computer-based simulations need to be driven by an active learning pedagogy (Bonwell \& Eison, 1991). The holistic aspect in particular validates one of the motivational building blocks for the development of the virtual island, which is to confront students with the complexities, paradoxes and tensions inherent in sustainable tourism development more broadly (Prince \& Ioannides, 2017), and in small islands in particular (Weaver, 2017). Furthermore, Felder's (1993) call that teaching innovation should include tools that serve traditionallyfocused learners as well as those with more kinaesthetic, visual, inductive, sensing, and global learning preferences, was positively reflected in this trial as respondents expressed strong support for a wider range of learning tools to be offered in today's tertiary education. Broader discussion during the interviews revealed that VR-based experiential education was considered a valuable tool in this context. For instance, full-immersion VR EE strongly appeals to visual learning through visual representations of the concepts and material (Felder \& Spurlin, 2005; Hsu, 2011), kinaesthetic learning by involving the learner physically with the to-be-learned information (Krätzig \& Arbuthnott, 2006), and inductive learning through its 
problem-based approach (Malmia et al, 2019; Prince \& Felder, 2006). While VR-based EE provides great potential in this context this exploratory study also identified the significant limitation of motion sickness on the user experience. Because motion sickness is positioned at the negative extreme of all three UX axes it was identified as the most pressing issue for full-immersion VR technology in an EE context; however, VR hardware continues to evolve and advances have already been achieved since the time of this exploratory trial.

As is not uncharacteristic of an exploratory study some research limitations need to be acknowledged. For instance, future studies should recruit a larger group of respondents and extend the duration in the virtual environment to both broaden and deepen the research findings. Additionally, a range of different VR headsets should be incorporated into the trial to assess the influence of the headset on the user experience.

\section{Conclusions}

This exploratory study sought to examine the capacity of full-immersion VR technology to foster EE as a key pedagogy for our rapidly changing world. The evolution of VR technology is increasingly enabling high fidelity and motivating EE learning activities to be offered at a relatively low cost, particularly when the logistical, resourcing, and ethical issues of alternative approaches are considered (Schott, 2017). The nuanced analysis of the identified positive and negative themes, through the lens of Hassenzahl and Tractinsky's (2006) adapted three UX facets, has provided valuable albeit indicative guidance where to concentrate refinement efforts. However, it is also evident that a great deal of further research on the user experience is required to extend our understanding of full-immersion VR technology as an important opportunity for EE and higher education more broadly.

All new technologies have a degree of novelty. In this context it is both important and encouraging that respondents identified several longer-term, as well as learning-focused benefits of the VR-based approach for EE. The ability to explore an environment with a holistic representation of a range of important features including spatial relationships, visual appearance, and a rich soundscape is clearly useful when seeking to create a cognitive space that supports a range of learning preferences as well as the achievement of a variety of learning outcomes. The ability to avoid the significant negative impacts on the climate, fragile environments, and socio-cultural fabric of communities typically associated with (educational) tourism (Andereck et al., 2005; Schott et al., 2010) should also not to be understated.

Because this exploratory study reports on the experiences of only a small group of users and on only one pedagogical context, the findings should be seen as indicative rather than as establishing an empirical evidence base. Both a mixed method, and a large-scale quantitative research approach, are now needed to build on this exploratory study. Such studies will serve to establish greater understanding of both the strengths and weaknesses of the adapted three facet UX framework as well as of the concept of fullimmersion VR technology for EE. As with all forms of EE, the context is key in designing effective activities that support the achievement of important learning outcomes for students. As such, further research is essential to not only gather evidence of the tool's concrete impact on identified learning objectives but also to explore the merit of other theoretical frameworks to both better understand and develop this new educational tool. Other interesting areas of research include the impact of operating virtual experiences in an explicitly collaborative mode with groups of students interacting directly in-world with avatars representing stakeholders in the reality-informed environment being explored. Although motion sickness was identified as a significant technical challenge, there are many research groups working on improvements aimed at reducing and mitigating this problem, which reinforces the prediction that (this time) VR technology is here to stay (Hilfert \& König, 2016).

\section{References}

Aggleton, J. P., \& Waskett, L. (1999). The ability of odours to serve as state - dependent cues for real world memories: Can Viking smells aid the recall of Viking experiences? British Journal of Psychology, 90(1), 1-7. https://doi.org/10.1348/000712699161170

Allison P., \& Seaman J. (2017). Experiential education. In M. Peters (Ed), Encyclopedia of educational philosophy and theory (pp. 1-6). Springer. https://doi.org/10.1007/978-981-287-532-7 449-1 
Andereck, K. L., Valentine, K. M., Knopf, R. C., \& Vogt, C. A. (2005). Residents' perceptions of community tourism impacts. Annals of Tourism Research, 32(4), 1056-1076. https://doi.org/10.1016/j.annals.2005.03.001

Bacca, J., Baldiris, S., Fabregat, R., Graf, S., \& Kinshuk. (2014). Augmented reality trends in education: A systematic review of research and applications. Journal of Educational Technology \& Society, 17(4), 133-149.

Bargas-Avila, J., \& Hornbaek, K. (2012). Foci and blind spots in user experience research. Interactions, 19(6), 24-27. https://doi.org/10.1145/2377783.2377790

Bevan, N. (2009, 1 January). What is the difference between the purpose of usability and user experience evaluation methods? Paper presented at the 12th IFIP TC13 Conference on Human-Computer Interaction, INTERACT'09, Uppsala, Sweden.

Bødker, S. (2015). Third-wave HCI, 10 years later-participation and sharing. Interactions, 22(5), $24-31$. https://doi.org/10.1145/2804405

Bonwell, C. C., \& Eison, J. A. (1991). Active learning: Creating excitement in the classroom. ASHEERIC Higher Education Report, Washington DC: School of Education and Human Development, George Washington University. .

Braun, V., \& Clarke, V. (2006). Using thematic analysis in psychology. Qualitative Research in Psychology, 3(2), 77-101. https://doi.org/10.1191/1478088706qp063oa

Buckley, R. (2000). Tourism in the most fragile environments. Tourism Recreation Research, 25(1), 3140. https://doi.org/10.1080/02508281.2000.11014898

Chickering, A., \& Gamson, Z. (1987). Seven principles of good practice in undergraduate education. AAHE Bulletin, 39(7), 3-7.

Choi, J. I., \& Hannafin, M. (1995). Situated cognition and learning environments: Roles, structures, and implications for design. Educational Technology Research and Development, 43(2), 53-69. https://doi.org/10.1007/BF02300472

Cummings, J. J., \& Bailenson, J. N. (2016). How immersive is enough? A meta-analysis of the effect of immersive technology on user presence. Media Psychology, 19(2), 272-309. https://doi.org/10.1080/15213269.2015.1015740

Dalgarno, B., \& Lee, M. J. W. (2010). What are the learning affordances of 3-D virtual environments? British Journal of Educational Technology, 41(1), 10-32. https://doi.org/10.1111/j.1467$\underline{\text { 8535.2009.01038.x }}$

D’Angelo, C., Rustein, D., Harris, C., Haertel, G., Bernard, R., \& Borokhovski, E. (2014). Simulations for STEM learning: Systematic review and meta-analysis. SRI Education.

de Freitas, S. (2008). Serious virtual worlds: A scoping study. Jisc.

Dewey, J. (1938). Education and experience. Simon and Schuster.

Dewey, J. (2004). Democracy and education. Dover Publications.

Dickey, M. D. (2005). Brave new (interactive) worlds: A review of the design affordances and constraints of two 3D virtual worlds as interactive learning environments. Interactive Learning Environments, 13, (1-2), 121-137. https://doi.org/10.1080/10494820500173714

Dredge, D., \& Schott, C. (2013). Academic agency and leadership in tourism higher education. Journal of Teaching in Travel \& Tourism, 13(2), 105-129. https://doi.org/10.1080/15313220.2013.786312

Edgar, T. W. \& Manz, D. O. (2017). Exploratory study. In T. W. Edgar, \& D. O Manz (Eds.), Research methods for cyber security (pp. 95-130). Syngress. https://doi.org/10.1016/B978-0-12-8053492.00004-2

Felder, R. M. (1993). Reaching the second tier. Journal of College Science Teaching, 23(5), 286-290.

Felder, R. M., \& Spurlin, J. (2005). Applications, reliability and validity of the index of learning styles. International Journal of Engineering Education, 21(1), 103-112.

Fereday, J., \& Muir-Cochrane, E. (2006). Demonstrating rigor using thematic analysis: A hybrid approach of inductive and deductive coding and theme development. International Journal of Qualitative Methods, 5(1), 80-92. https://doi.org/10.1177/160940690600500107

Forlizzi, J., \& Battarbee, K. (2004, 1-4 August). Understanding experience in interactive systems. Paper presented at the Conference on Designing Interactive Systems (DIS 04): Processes, practices, methods, and techniques (ACM), Cambridge, MA., 261-268. https://doi.org/10.1145/1013115.1013152

Freina, L., \& Ott, M. (2015, 23-24 April). A literature review on immersive virtual reality in education: state of the art and perspectives. Paper presented at the International Scientific Conference eLearning and Software for Education, Bucharest, 133-141. https://doi.org/10.12753/2066-026X-15-020 
Greeno, J. G., Moore, J. L., \& Smith, D. R. (1993). Transfer of situated learning. In D. K. Detterman, \& R. J. Sternberg (Eds.), Transfer on trial: Intelligence, cognition, and instruction (pp. 99-167). Ablex Publishing.

Hanson, S., \& Moser, S. (2003). Reflections on a discipline-wide project: Developing active learning modules on the human dimensions of global change. Journal of Geography in Higher Education, 27(1), 17-38. https://doi.org/10.1080/0309826032000062441

Hassenzahl, M. (2003). The thing and I: Understanding the relationship between user and product. In M. A., Blythe, K., Overbeeke, A. F., Monk, \& P. C. Wright (Eds.), Funology. Human-Computer Interaction Series (Vol 3, pp. 31-42). Springer. https://doi.org/10.1007/1-4020-2967-5_4

Hassenzahl, M., \& Roto, V. (2007). Being and doing: A perspective on user experience and its measurement. Interfaces, 72(Autumn), 10-12.

Hassenzahl, M., \& Tractinsky, N. (2006). User experience - a research agenda. Behaviour \& Information Technology, 25(2), 91-97. https://doi.org/10.1080/01449290500330331

Heilig, M. (1962). Sensorama simulator. http://www.mortonheilig.com/SensoramaPatent.pdf

Hew, K. F., \& Cheung, W. S. (2010). Use of three-dimensional (3-D) immersive virtual worlds in K-12 and higher education settings: A review of the research. British Journal of Educational Technology, 41(1), 33-55. https://doi.org/10.1111/j.1467-8535.2008.00900.x

Hilfert, T., \& König, M. (2016). Low-cost virtual reality environment for engineering and construction. Visualization in Engineering, 4(1), 1-18. https://doi.org/10.1186/s40327-015-0031-5

Holley, D., Hobbs, M., \& Menown, C. (2016). The augmented library: Motivating STEM students. Networks, 19, 77-84.

Hsu, L. (2011). The perceptual learning styles of hospitality students in a virtual learning environment: The case of Taiwan. Journal of Hospitality, Leisure, Sports and Tourism Education, 10(1), 114-127.

Itin, C. M. (1997). The orientation of social work faculty to the philosophy of experiential education in the classroom (Doctoral dissertation). University of Denver, Colorado, CO.

Jensen, L., \& Konradsen, F. (2018). A review of the use of virtual reality head-mounted displays in education and training. Education and Information Technologies, 23(4), 1515-1529. https://doi.org/10.1007/s10639-017-9676-0

Kaye, J. J. (2004). Making scents: Aromatic output for HCI. Interactions, 11(1), 48-61.

Khanna, R., Guler, I., \& Nerkar, A. (2016). Fail often, fail big, and fail fast? Learning from small failures and R\&D performance in the pharmaceutical industry. Academy of Management Journal, 59(2), 436459. https://doi.org/10.5465/amj.2013.1109

Kolb, D. A. (1984). Experiential learning: experience as the source of learning and development. Prentice Hall.

Krätzig, G. P., \& Arbuthnott, K. D. (2006). Perceptual learning style and learning proficiency: A test of the hypothesis. Journal of Educational Psychology, 98(1), 238-246. https://doi.org/10.1037/0022$\underline{0663.98 .1 .238}$

Lanier, J. (1989). Virtual reality: A status report. In L. Jacobson (Ed.), Cyberarts: Exploring art and technology (pp. 272-279). Miller Freeman.

Law, E. L. C., \& Van Schaik, P. (2010). Modelling user experience-An agenda for research and practice. Interacting with Computers, 22(5), 313-322. https://doi.org/10.1016/j.intcom.2010.04.006

Loke, S.-K. (2015). How do virtual world experiences bring about learning? A critical review of theories. Australasian Journal of Educational Technology, 31(1), 112-122. https://doi.org/10.14742/ajet.2532

Lombard, M., \& Ditton, T. (1997). At the heart of it all: The concept of presence. Journal of ComputerMediated Communication, 3(2). https://doi.org/10.1111/j.1083-6101.1997.tb00072.x

Louis, K. S., \& Gordon, M. F. (2006). Aligning student support with achievement goals: The secondary principal's guide. Corwin Press.

Malmia, W., Makatita, S. H., Lisaholit, S., Azwan, A., Magfirah, I., Tinggapi, H; \& Umanailo, B. (2019). Problem-based learning as an effort to improve student learning outcomes. International Journal of Scientific \& Technology Research, 8(9), 1140-1143.

Martin-Gutiérrez, J., Mora, C. E., Añorbe-Diaz, B., \& González-Marrero, A. (2017). Virtual technologies trends in education. EURASIA Journal of Mathematics Science and Technology Education, 13(2), 469-486. https://doi.org/10.12973/eurasia.2017.00626a

Martín-Gutiérrez, J., Saorín, J. L., Contero, M., Alcaniz, M., Pérez-López, D. C., \& Ortega, M. (2010). Design and validation of an augmented book for spatial abilities development in engineering students. Computers \& Graphics, 34(1), 77-91. https://doi.org/10.1016/j.cag.2009.11.003 
Merchant, Z., Goetz, E. T., Cifuentes, 1., Keeny-Kennicutt, W., \& Davis, T. J. (2014). Effectiveness of virtual reality-based instruction on students' learning outcomes in K-12 and higher education: A metaanalysis. Computers \& Education, 70, 29-40. https://doi.org/10.1016/j.compedu.2013.07.033

Meyer, J., \& Land, R. (2003). Threshold concepts and troublesome knowledge: Linkages to ways of thinking and practising within the disciplines. University of Edinburgh.

Miettinen, R. (2000). The concept of experiential learning and John Dewey's theory of reflective thought and action. International Journal of Lifelong Education, 19(1), 54-72. https://doi.org/10.1080/026013700293458

Murray, H. J. (1998). Immersion. H. J. Murray (Ed.), Hamlet on the holodeck (pp. 97-125). MIT Press.

Obrist, M. (2017). Mastering the senses in HCI: Towards multisensory interfaces. Proceedings of the 12th Biannual Conference on Italian SIGCHI Chapter, Cagliari, Italy, 1-2. https://doi.org/10.1145/3125571.3125603

Pearson, D. R., \& Beckham, J. (2005). Negligent liability issues involving colleges and students: Balancing the risks and benefits of expanded programs and heightened supervision. NASPA Journal, 42(4), 460-477. https://doi.org/10.2202/1949-6605.1535

Piaget, J. (1976). Piaget's theory. In B. Inhelder, H. H. Chipman, \& C. Zwingmann (Eds.), Piaget and his school (pp. 11-23). Springer. https://doi.org/10.1007/978-3-642-46323-5_2

Picard, R. W. (1997). Affective computing. MIT Press.

Prince, M. J., \& Felder, R. M. (2006). Inductive teaching and learning methods: Definitions, comparisons, and research bases. Journal of Engineering Education, 95(2), 123-138. https://doi.org/10.1002/j.21689830.2006.tb00884.x

Prince, S., \& Ioannides, D. (2017). Contextualizing the complexities of managing alternative tourism at the community-level: A case study of a nordic eco-village. Tourism Management, 60, 348-356. https://doi.org/10.1016/j.tourman.2016.12.015

Reason, P., \& Bardbury, H. (2008). The SAGE handbook of action research participative inquiry and practice (2nd ed.). Sage Publications.

Rebelo, F., Noriega, P., Duarte, E., \& Soares, M. (2012). Using virtual reality to assess user experience. Human Factors, 54(6), 964-982. https://doi.org/10.1177/0018720812465006

Roberts, J. (2018). From the editor: The possibilities and limitations of experiential learning research in higher education. Journal of Experiential Education, 41(1), 3-7. https://doi.org/10.1177/1053825917751457

Schott, C. (2015). Digital immersion for sustainable tourism education: A roadmap to virtual fieldtrips. In G. Moscardo, \& P. Benckendorff (Eds.), Education for sustainability in tourism: A handbook of processes, resources, and strategies (pp. 213-227). Springer.

Schott, C. (2017). Virtual fieldtrips and climate change education for tourism students. Journal of Hospitality, Leisure, Sport \& Tourism Education, 21(A), 13-22. https://doi.org/10.1016/j.jhlste.2017.05.002

Schott, C., \& Marshall, S. (2018). Virtual reality and situated experiential education: A conceptualisation and exploratory trial. Journal of Computer Assisted Learning, 34(6), 843-852. https://doi.org/10.1111/jcal.12293

Schott, C., Reisinger, A., \& Milfont, T. L. (2010). Tourism and climate change. In C. Schott (Ed.), Tourism and the implications of climate change: Issues and actions (pp. 1-24). Emerald Group Publishing Limited. https://doi.org/10.1108/S2042-1443(2010)0000003004

Shin, D. (2018). Empathy and embodied experience in virtual environment: To what extent can virtual reality stimulate empathy and embodied experience? Computers in Human Behaviour, 77, 64-73. https://doi.org/10.1016/j.chb.2017.09.012

Sitzmann, T. (2011). A meta-analytic examination of the instructional effectiveness of computer-based simulation games. Personnel Psychology, 64(2), 489-528. https://doi.org/10.1111/j.1744$\underline{6570.2011 .01190 . \mathrm{x}}$

Slater, M. (2009). Place illusion and plausibility can lead to realistic behaviour in immersive virtual environments. Philosophical Transactions of the Royal Society London, 364(1535), 3549-3557. https://doi.org/10.1098/rstb.2009.0138

Slater, M., \& Sanchez-Vives, M. V. (2016). Enhancing our lives with immersive virtual reality. Frontiers in Robotics and AI, 3(74), 1-47. https://doi.org/10.3389/frobt.2016.00074

Stainfield, J., Fisher, P., Ford, B., \& Solem, M. (2000). International virtual field trips: A new direction? Journal of Geography in Higher Education, 24(2), 255-262. https://doi.org/10.1080/713677387

Sutherland, I. E. (1965). The ultimate display. Proceedings of the International Federation of Information Processing Congress, New York City, NY, 506-508. 
Trinh, M. (2019). Learning identity, flexibility, and lifelong experiential learning. Oxford Research Encyclopedia of Business and Management. https://doi.org/10.1093/acrefore/9780190224851.013.187

Tussyadiah, I. P., Wang, D., Jung, T. H., \& tom Dieck, M. C. (2018). Virtual reality, presence, and attitude change: Empirical evidence from tourism. Tourism Management, 66, 140-154.

https://doi.org/10.1016/j.tourman.2017.12.003

Vermeeren, A. P., Roto, V., \& Väänänen, K. (2016). Design-inclusive UX research: Design as a part of doing user experience research. Behaviour \& Information Technology, 35(1), 21-37. https://doi.org/10.1080/0144929X.2015.1081292

Vi, C. T., Ablart, D., Arthur, D., \& Obrist, M. (2017). Gustatory interface: The challenges of 'how' to stimulate the sense of taste. Proceedings of the 2nd ACM SIGCHI International Workshop on Multisensory Approaches to Human-Food Interaction, Glasgow, UK, 13 November, 29-33. https://doi.org/10.1145/3141788.3141794

Vunidilo, T. S. (2010). The indigeneity of archaeological research in Fiji: Issues and opportunities (Doctoral dissertation). University of Waikato, New Zealand.

Weaver, D. B. (2017). Core-periphery relationships and the sustainability paradox of small island tourism. Tourism Recreation Research, 42(1), 11-21. https://doi.org/10.1080/02508281.2016.1228559

Wlodkowski, R. J. (2011). Enhancing adult motivation to learn: A comprehensive guide for teaching all adults. John Wiley \& Sons.

Wurdinger, S., \& Rudolph, J. (2009). Teaching practices that improve student learning: Five experiential approaches. Journal of Teaching and Learning, 6(1), 1-13. https://doi.org/10.22329/JTL.V6I1.505

Corresponding author: Christian Schott, $\underline{\text { Christian.schott@vuw.ac.nz }}$

Copyright: Articles published in the Australasian Journal of Educational Technology (AJET) are available under Creative Commons Attribution Non-Commercial No Derivatives Licence (CC BY-NCND 4.0). Authors retain copyright in their work and grant AJET right of first publication under CC BYNC-ND 4.0.

Please cite as: Schott, C., \& Marshall, S. (2021). Full-immersion virtual reality for experiential education: An exploratory user experience analysis. Australasian Journal of Educational Technology, 37(1), 96-110. https://doi.org/10.14742/ajet.5166 